\title{
Emprego e Desigualdade de Rendimentos no Brasil: uma Análise a partir da Estrutura de Ocupações
}

\section{Employment and Earnings Inequality in Brazil: an Analysis from the Occupations Structure}

\author{
Juliana Jacobowiski Martins* \\ Marina Silva da Cunha**
}

\begin{abstract}
Resumo: O objetivo deste trabalho é discutir o emprego e a desigualdade de rendimentos entre as ocupações, buscando identificar também diferenças entre homens e mulheres na estrutura de emprego. Considerando-se a reestruturação ocorrida na Pesquisa Nacional por Amostra de Domicílio (PNAD) em 2002, com base na Classificação Brasileira das Ocupações (CBO), as informações desse ano são comparadas às de 2012. O emprego se alterou entre as ocupações, com destaque, de um lado, para o crescimento daqueles ocupados nas ciências e artes e, de outro lado, para a queda do emprego dos trabalhadores agrícolas. $\mathrm{Na}$ análise individual de cada determinante, os resultados da pesquisa sugerem queda da desigualdade como um todo e da parcela explicada pela ocupação, que se firma como um dos principais determinantes da desigualdade de rendimentos no Brasil. As mulheres possuem os menores rendimentos e níveis de desigualdade, e, entre as ocupações, há diferenciais maiores entre elas que entre os homens. Por fim, é possível constatar que a queda dos diferenciais de rendimento entre as ocupações ocorreu devido à melhoria em outros determinantes, como a maior homogeneidade no capital humano dos indivíduos, que ficaram mais qualificados, e às quedas dos diferenciais intersetoriais e entre homens e mulheres.
\end{abstract}

Palavras-chave: Desigualdade de rendimentos. Diferenciais compensatórios. Mercado de trabalho.

\begin{abstract}
The objective of this paper is to discuss employment and earnings inequality among the occupations, also seeking to identify differences between men and women in employment structure. Considering the restructuring in the National Survey of Households (PNAD) in 2002 of the Brazilian Classification of Occupations (CBO), information from this year is compared to 2012. The employment changed between occupations, especially on one side, to the growth of those employed in science and arts and on the other hand, to the fall in employment of agricultural workers. In the individual analysis of each determinant, the survey results suggest a lower inequality as a whole and the part explained by the occupation, which has established itself as a major determinant of income inequality in

* Graduada em Ciências Econômicas pela Universidade Estadual de Maringá (UEM). E-mail: ju.jacobowiski@hotmail.com

** Pós-doutora em Economia do Trabalho pela Universidade de Brasília (UnB). Doutora em Economia Aplicada pela Universidade de São Paulo (USP). Professora titular do Departamento de Economia e do Programa de Pós-graduação em Ciências Econômicas da Universidade Estadual de Maringá (UEM).E-mail: mscunha@uem.br
\end{abstract}


Brazil. Women have the lowest income and level of inequality, and between occupations there are greater differences between them. Finally, it was established that the fall in yield spreads between occupations was due to improvement in other determinants, such as greater homogeneity in the human capital of individuals, who were more qualified, and the falls of differentials, inter-sector and between men and women.

Keywords: Bank credit. Monetary policy. Panel data.

JEL Classification: E51; E52; G21.

\section{Introdução}

Desde Adam Smith, em seu livro clássico A riqueza das nações: uma investigação sobre sua natureza e suas causas, publicado em 1776, as diferenças de remuneração no mercado de trabalho entre as ocupações tem chamado atenção dos estudiosos de economia, conforme destacam Katz e Autor (1999). Para Smith (1995), tais diferenças ocorrem devido às condições de trabalho, ao custo de aprendizagem, à estabilidade, ao grau de confiança e à probabilidade de sucesso, mas também são influenciadas pelas políticas de proteção a determinadas classes de trabalhadores vigentes à época e pelo equilíbrio entre oferta e demanda no mercado de trabalho. Mills (1979), que faz uma análise histórica da nova classe média do início do século XX e do papel dos colarinhos brancos, aponta que a importância da ocupação no mercado de trabalho pode ir além do seu retorno econômico, pois também representaria prestígio social, que se refletiria na maneira de se vestir e nos relacionamentos com as autoridades, além da forma de impor sua vontade em relação aos seus subordinados e até nas relações sociais. Em uma síntese mais atual, conforme Borjas (2012), os diferenciais de renda relacionados à estrutura de ocupações são denominados de compensatórios, pois buscariam compensar monetariamente os trabalhadores por características de cada ocupação.

Conforme a literatura internacional, as mudanças na estrutura de ocupações têm elevado a desigualdade de rendimentos. Para Coelli e Borland (2016), a expansão de ocupações com maior nível de qualificação, de 1966 até 2011, tem contribuído para aumentar a desigualdade de rendimento na Austrália, alterando tanto a composição, quanto os rendimentos médios das ocupações. Da mesma forma, Autor (2014a) observa a maior demanda por trabalhadores mais qualificados no mercado de trabalho americano, em mais 16 países da comunidade europeia, de 1993 para 2010, em função da introdução de novas tecnologias. Essas evidências estão de acordo com a hipótese de mudança tecnológica com viés para o trabalho qualificado, conforme descrita por Acemoglu e Autor (2010), e maiores retornos aos trabalhadores mais qualificados, Goldin e Katz (2009), com o aumento dos rendimentos das ocupações mais e menos qualificadas e redução dos rendimentos daquelas com qualificação média, as quais também estariam per- 
dendo postos de trabalho. Com isso, haveria uma polarização tanto do emprego, quanto dos rendimentos e uma complementaridade das ocupações com baixa e alta qualificação, o que teria levado, nos países mais desenvolvidos, a uma elevação da desigualdade na distribuição dos rendimentos. ${ }^{1}$

No Brasil, a literatura sobre a estrutura de ocupações ainda é escassa. Nessa linha de estudos há o trabalho de Flori (2007), que verifica a importância das ocupações para a desigualdade de rendimentos, de 1984 para 2001, observando queda do emprego em ocupações com menor qualificação, como no setor de serviços. Já o trabalho de Maia e Quadros (2010) constata uma redução relativa nos rendimentos mais elevados e dos mais qualificados no início da década de 1980 para o início da de 2000 . Observam, ainda, que 49\% da desigualdade na distribuição de rendimentos se deviam à diferenciação entre as ocupações no ano de 2001. Nessa mesma linha de estudos, Comin (2015) também constata redução no emprego nas categorias com trabalhadores com menor qualificação de 1981 para 2011.

De fato, a desigualdade de rendimentos é um tema relevante na discussão sobre o mercado de trabalho brasileiro, devido ao seu nível ainda elevado, mesmo com a redução no período recente. Ademais, entre os principais determinantes da distribuição de renda no país se encontram as desigualdades resultantes da estrutura de ocupações. Nesse contexto, o objetivo desta pesquisa é analisar as transformações do mercado de trabalho brasileiro com foco na desigualdade de rendimentos entre as ocupações, verificando as modificações tanto no emprego quanto nos rendimentos. Como, a partir de 2002, a Pesquisa Nacional por Amostra de Domicílios (PNAD) do IBGE passou a adotar a Classificação Brasileira de Ocupações (CBO) para classificar as ocupações, são utilizadas as informações da PNAD de 2002 e de 2012. Dessa forma, este trabalho contribui com o debate sobre o tema abordando um período mais recente, com a nova classificação do IBGE, além de adotar também a perspectiva das diferenças de gênero.

No início dos anos 2000, segundo Machado, Oliveira e Wajnman (2005), apesar dos avanços, as mulheres se destacavam em atividades manuais e pouco valorizadas no mercado de trabalho, tais como no trabalho doméstico, cuja ocupação compreendia $16,57 \%$ do sexo feminino em 2003. Para Soares e Oliveira (2004), no mercado de trabalho brasileiro ainda predomina a desigualdade de gênero e a segregação ocupacional, com ocupações tipicamente "femininas", como de emprego doméstico, atividades de escritório, prestação de serviços de estética, hotelaria e alimentação, comércio, saúde, educação, vestuário e decoração, en-

1 Porém, tanto Autor (2014a) quanto Goldin e Katz (2009) advertem que as mudanças na estrutura de ocupações e o aumento da desigualdade nos Estados Unidos não podem ser explicados apenas pelas mudanças tecnológicas e incluem outros fatores tais como a imigração, o comércio internacional e o colapso do mercado imobiliário, com a respectiva crise econômica, que se tornou mundial. 
tre outras. Mais recentemente, para Kubrusly (2015), que analisa as diferenças no mercado de trabalho feminino e masculino em 2002 e 2012, não houve redução das diferenças entre mulheres e homens, por exemplo, em relação à taxa de desocupação e à proporção de trabalho não remunerado, que é maior entre elas.

Conforme Bruschini e Lombardi (1996), com relação à participação feminina no mercado de trabalho, nota-se que, se de um lado, a queda da fecundidade desempenha um papel importante para a ampliação da atividade da mulher, deixando-a mais disponível, de outro, a manutenção do modelo familiar em que cabe à mulher a responsabilidade doméstica e socializadora obriga-a a articular o seu papel familiar e profissional, inibindo sua maior inserção econômica. Ademais, quando buscam trabalho ainda se deparam com outros aspectos que as discriminam, tais como barreiras no acesso a cargos de comando e chefia e menores salários em relação aos colegas homens.

Este estudo está dividido em quatro seções, além desta introdução: na segunda se descrevem a metodologia utilizada e a fonte de dados; na terceira se faz uma análise descritiva buscando traçar um perfil de cada ocupação de acordo com as características pessoais e posto de trabalho dos ocupados; na quarta se apresentam e discutem os resultados obtidos pelas regressões e pela decomposição da desigualdade de rendimentos; por fim, na quinta se traçam as considerações finais.

\section{Procedimentos Metodológicos}

No trabalho são analisadas informações de 2002 e 2012 da PNAD, que têm abrangência nacional. ${ }^{2}$ São considerados os rendimentos do trabalho principal, na semana de referência, dos indivíduos com idade de 15 até 65 anos. ${ }^{3}$

Buscando captar a desigualdade em função dos diferenciais compensatórios, associada a diferenças nos postos de trabalho, são consideradas nove ocupações do mercado de trabalho brasileiro, de acordo com a $\mathrm{CBO}$, sendo elas: dirigentes em geral (dir), profissionais das ciências e das artes ( $p c a)$, técnicos de nível médio (tmed), trabalhadores de serviços administrativos (sadm), trabalhadores dos serviços (serv), vendedores e prestadores de serviços do comércio (com), trabalhadores agrícolas (agro), trabalhadores da produção de bens e serviços industriais e de reparação e manutenção (tprod) e membros das forças armadas e auxiliares (mil).

Ademais, há outros determinantes dos diferenciais de rendimentos, como aqueles relacionados às características não produtivas dos trabalhadores - como

$2 \quad$ A justificativa para o período analisado se deve ao fato da que a PNAD modificou sua metodologia de coleta de dados em relação às ocupações a partir do ano de 2002. Segundo Maia e Quadros (2010), novas ocupações foram criadas, algumas extintas e outras readequadas em novas ocupações, o que limita a comparação com o período anterior à nova classificação.

Os rendimentos de 2002 foram corrigidos para setembro de 2012, considerando-se a sugestão de Corseuil e Foguel (2002). 
gênero e cor -, às características produtivas dos trabalhadores - como educação e experiência - e às características dos postos de trabalho - como setor de atividade e localização. Os primeiros determinantes estão relacionados com a discriminação no mercado de trabalho, uma vez que remuneram de forma diferenciada indivíduos igualmente produtivos. Por sua vez, educação e experiência representam uma proxy do capital humano individual. ${ }^{4}$ Além desses, são considerados, ainda, outros determinantes da desigualdade relacionados às características produtivas dos indivíduos, à discriminação e à segmentação.

A educação é representada pela educação formal, definida em intervalos de anos de estudo de: 0 a 4 anos (analfabeto e ensino básico ); 5 a 8 anos (ensino fundamental); 9 a 11 anos (ensino médio); ou 12 ou mais anos de estudo (graduação ou mais). Por sua vez, a idade (idade) e seu quadrado (idade ${ }^{2}$ ), também em anos, representam a experiência do indivíduo. No caso da idade, que reflete a experiência do indivíduo, são definidos ainda dois subgrupos: os jovens, de 15 até 25 anos, e os adultos, de 26 até 65 anos. Para a discriminação, são analisados o sexo, homem ou mulher, e a raça/cor, branca ou não branca, do indivíduo, em que entre brancos estão os brancos e amarelos e, entre os não brancos, os negros, pardos e indígenas. Para se diferenciar os sexos, incluiu-se uma binária (homem) com valor igual a 1 quando o indivíduo era homem, e zero caso contrário; por sua vez, para se diferenciar a raça, incluiu-se uma binária com valor igual a 1 para os trabalhadores brancos (branco) e zero caso contrário. Por fim, a segmentação é estudada considerando-se os setores da economia: setor primário (agricultura), secundário (indústria) e terciário (serviços) e as grandes regiões geográficas do país, Norte, Nordeste, Sul, Sudeste e Centro-Oeste.

Para se homogeneizar os dados das pesquisas de 2002 e 2012, a área rural da região Norte, em 2012, foi excluída, uma vez que não fazia parte da PNAD de 2002. Foram excluídos também os indivíduos com alguma informação não declarada ou incompleta. Assim, após esse processo, no ano de 2002 havia 145.682 indivíduos na amostra da PNAD, enquanto a população estimada, com base nos pesos disponibilizados na pesquisa, foi de 65.772.050. Para o ano de 2012, a amostra e população estimada foram iguais a 160.954 e 90.220 .759 , respectivamente.

Para se analisar o efeito da estrutura ocupacional na desigualdade de rendimentos total são consideradas duas abordagens. Inicialmente, a desigualdade é decomposta a partir das medidas de desigualdade de Theil, com os índices $T$ de Theil e $L$ de Theil. Conforme Hoffmann (1998), o primeiro índice se caracteriza por ser mais sensível a modificações na cauda superior da distribuição, com pessoas com os maiores rendimentos, os mais ricos, e o último por ser mais sensível a modificações na cauda inferior da distribuição, com pessoas com os menores rendimentos. Portanto, essas medidas de desigualdade são obtidas para cada de-

$4 \quad$ Sobre a teoria do capital humano, ver Becker (1962), Schultz (1973) e Mincer (1974). 
terminante estudado considerando seus respectivos subgrupos. Ainda, para se caracterizar a distribuição dos rendimentos também se calcula o índice de Gini, que, por sua vez, é mais sensível a mudanças na moda da distribuição.

Considere-se uma população com $n$ indivíduos, com a renda do i-ésimo indivíduo denotada por $w_{i}$ e com a renda média representada por $\mu$. Segundo Hoffmann (1998), o índice de desigualdade de Gini pode ser expresso por:

$$
G=\frac{2}{n^{2} \mu} \sum_{i=1}^{n} i w_{i}-\left(1+\frac{1}{n}\right)
$$

Conforme Hoffmann (1998) e Moorkherjee e Shorrocks (1982), os índices L de Theil $\left(I_{0}\right)$ e o $T$ de Theil $\left(I_{1}\right)$ estão incluídos em uma classe de medidas decomponível em uma parcela que explica a desigualdade dentro dos grupos da população e outra entre grupos. Considerando-se a proporção de indivíduos no grupo $k$, $v_{k}=n_{k} / n$, e a renda média relativa do grupo $k$ em relação à população total, $\lambda_{k}=\mu_{k} / \mu$, essa decomposição pode ser descrita como:

$$
\begin{aligned}
& I_{0}=\sum_{k} v_{k} I_{0}^{k}+\sum_{k} v_{k} \log \left(\frac{1}{\lambda_{k}}\right) \\
& I_{1}=\sum_{k} v_{k} \lambda_{k} I_{1}^{k}+\sum_{k} v_{k} \lambda_{k} \log \lambda_{k}
\end{aligned}
$$

A primeira parcela dessas equações é uma soma ponderada da desigualdade dentro dos grupos e a segunda corresponde a uma média ponderada da desigualdade entre os grupos. Essa última fração da desigualdade reflete o efeito puro de cada agrupamento ou variável analisada. Além da ocupação, neste trabalho são consideradas as variáveis gênero, cor/raça, idade, educação, grandes regiões e setor de atividade. Salienta-se que a subdivisão da população em grupos se constitui em um importante instrumento de análise da desigualdade, uma vez que pode indicar a origem de mudanças. A desigualdade entre grupos é também denominada de contribuição bruta para a desigualdade total, em que cada variável é analisada isoladamente.

Em seguida, é utilizado o modelo de regressão linear múltipla, estimado por meio do método de mínimos quadrados ponderados, usando o fator de expansão associado a cada observação da amostra, em cada ano analisado. ${ }^{5}$ Nesse modelo,

5 A aplicação do método de mínimos quadrados ordinários é adequada para a estimação de diferenciais de salários e rendimentos, pois tem sido utilizado na literatura empírica sobre 
a variável dependente é o logaritmo dos rendimentos $(L w)$, seguindo a equação minceriana, proposta por Mincer (1974), em que se tem a seguinte especificação:

$$
\begin{aligned}
L w_{i}= & \alpha_{i}+\gamma_{1} \text { dir }_{i}+\gamma_{2} \text { pca }_{i}+\gamma_{3} \text { med }_{i}+\gamma_{4} \text { adm }_{i}+\gamma_{5} \text { serv }_{i}+\gamma_{6} \text { com }_{i}+\gamma_{7} \text { tprod }_{i}+ \\
& \gamma_{8} \text { mil }_{i}+\gamma_{9} \text { ensino fundamental }_{i}+\gamma_{10} \text { ensino médio }_{i}+\gamma_{11} \text { graduação } \\
& \text { ou } \text { mais }_{i}+\gamma_{12} \text { idade }_{i}+\gamma_{13} \text { idade }_{i}+\gamma_{14} \text { homem }_{i}+\gamma_{15} \text { branco }_{i} \\
& +\gamma_{16} \text { indústria }_{i}+\gamma_{17} \text { serviços }_{i}+\gamma_{18} \text { nordeste }_{i}+\gamma_{19} \text { sudeste }_{i}+\gamma_{20} \text { sul }_{i}+ \\
& \gamma_{21} \text { centro-oeste }+\varepsilon_{i},
\end{aligned}
$$

em que $\alpha$ e os $\gamma$ são os parâmetros, $\varepsilon$ é o termo aleatório e $i$ indica o indivíduo. São incluídas como variáveis de controle, além da idade e seu quadrado, variáveis binárias para captar as diferenças entre as ocupações, a escolaridade, o sexo, a raça, a região de residência e o setor de atividade. Assim, as categorias de referência ou omitidas em cada determinante analisado são os trabalhadores agrícolas, indivíduos com 0 a 4 anos de estudo, mulheres, não brancos, setor agrícola e região Norte.

Buscando-se complementar a análise da desigualdade de rendimentos, se calcula também a contribuição marginal, que considera a proporção explicada na soma de quadrados da regressão por cada fator, quando este é incluído no modelo, em que os demais fatores, considerados relevantes para a explicação da desigualdade, já estão incluídos. ${ }^{6}$

\section{Descrição dos Dados}

Inicialmente, verifica-se relativa estabilidade na composição do emprego segundo as ocupações, de 2002 para 2012, conforme a Tabela 1, em que se pode destacar o aumento do emprego naquelas com maior qualificação.

diferenciais de rendimento de acordo com a estrutura de ocupações, conforme os estudos de Flori (2007) e Flori e Menezes-Filho (2008). Ademais, a contribuição marginal, também utilizada por Hoffmann (2000) e Ramos (2007), é obtida a partir das somas de quadrados da estimativa por mínimos quadrados.

6 Ver Hoffmann (2000) para outros detalhes. 
Tabela 1 - Composição do emprego por ocupação: Brasil (2002-2012)

\begin{tabular}{lrr}
\hline Ocupação & $\mathbf{2 0 0 2}$ & $\mathbf{2 0 1 2}$ \\
\hline Dirigentes em geral (dir) & 5,69 & 5,26 \\
Profissionais das ciências e das artes (pca) & 6,56 & 9,36 \\
Técnicos de nível médio (tmed) & 8,23 & 7,22 \\
Trabalhadores de serviços administrativos (sadm) & 8,77 & 10,94 \\
Trabalhadores dos serviços (serv) & 21,79 & 21,34 \\
Vendedores e prestadores de serviços do comércio (com) & 9,77 & 10,15 \\
Trabalhadores agrícolas (agro) & 12,22 & 8,21 \\
Trabalhadores da produção e da indústria (tprod) & 26,04 & 26,56 \\
Membros das forças armadas e auxiliares (mil) & 0,93 & 0,96 \\
\hline
\end{tabular}

Fonte: Elaboração própria a partir de dados da PNAD/IBGE.

Considerando-se as nove ocupações estudadas, em 2002 os trabalhadores da produção e da indústria são predominantes, com $26,04 \%$ dos indivíduos ocupados, seguidos pelos trabalhadores dos serviços $(21,79 \%)$, trabalhadores agrícolas $(12,22 \%)$, vendedores e prestadores de serviços do comércio $(9,77 \%)$, trabalhadores dos serviços administrativos ( $8,77 \%)$, técnicos de nível médio $(8,23 \%)$, profissionais das ciências e das artes (6,56\%), dirigentes em geral (5,69\%) e membros das forças armadas e auxiliares (0,93\%). Em 2012, apesar das poucas modificações na estrutura de ocupações em relação a 2002, merece destaque o aumento do emprego para os profissionais das ciências e das artes, representando a maior variação positiva entre as ocupações $(42,83 \%)$. Em contrapartida, os trabalhadores agrícolas apresentaram a maior queda na participação no emprego (32,79\%).

Esse movimento de queda da participação dos indivíduos, especialmente em ocupações predominantemente compostas por pessoas com nível fundamental e médio de escolaridade, somado a uma melhoria no nível de escolaridade e da ocupação profissionais das ciências e das artes sugere que os indivíduos estão investindo mais tempo no seu nível de escolaridade, sobretudo no ensino superior. Esse fato está de acordo com a expansão do sistema educacional brasileiro nesse período, que, de um lado, necessita desses profissionais e, de outro, está formando mais profissionais para o mercado de trabalho. ${ }^{7}$ Nessa perspectiva, também é in-

$7 \quad$ De acordo com Veloso (2011), enquanto 64\% dos jovens de 15 até 17 anos frequentavam a escola em 1995, no ano de 2009 esse índice atingiu 85\%. Além disso, a conclusão no ensino fundamental aumentou de $29 \%$ para $61 \%$, de 1995 a 2007, respectivamente, e no ensino médio evoluiu de $17 \%$ para 45\% no mesmo período. Com relação ao ensino superior, segundo Queiroz et al. (2013), 
cluída a queda no emprego dos técnicos de nível médio e os trabalhadores dos serviços e, por outro lado, o aumento dos trabalhadores de serviços administrativos.

Ainda pode ser destacada a queda de 0,43 pontos percentuais para os cargos de dirigentes e ampliação de 2,16 pontos percentuais para trabalhadores dos serviços administrativos. Vendedores e prestadores de serviços do comércio, membros das forças armadas e auxiliares e os trabalhadores da produção e da indústria relativamente mantiveram praticamente a mesma proporção no período analisado.

Na Tabela 2 se encontram a composição dos ocupados no mercado de trabalho brasileiro segundo cada determinante da desigualdade de rendimentos analisado, tanto para o total dos trabalhadores, quanto para cada uma das nove ocupações estudadas, estabelecidas na metodologia e analisadas na Tabela 1.

considerando informações do INEP, incluindo o ensino à distância, em 2000 haviam 2.694.245 alunos matriculados e, em 2010, um total de 6.374.299, dos quais $67 \%$ em estabelecimentos particulares e os restantes 33\% em estabelecimentos públicos, em 2000, e 74\% e 26\%, em 2010, respectivamente. 


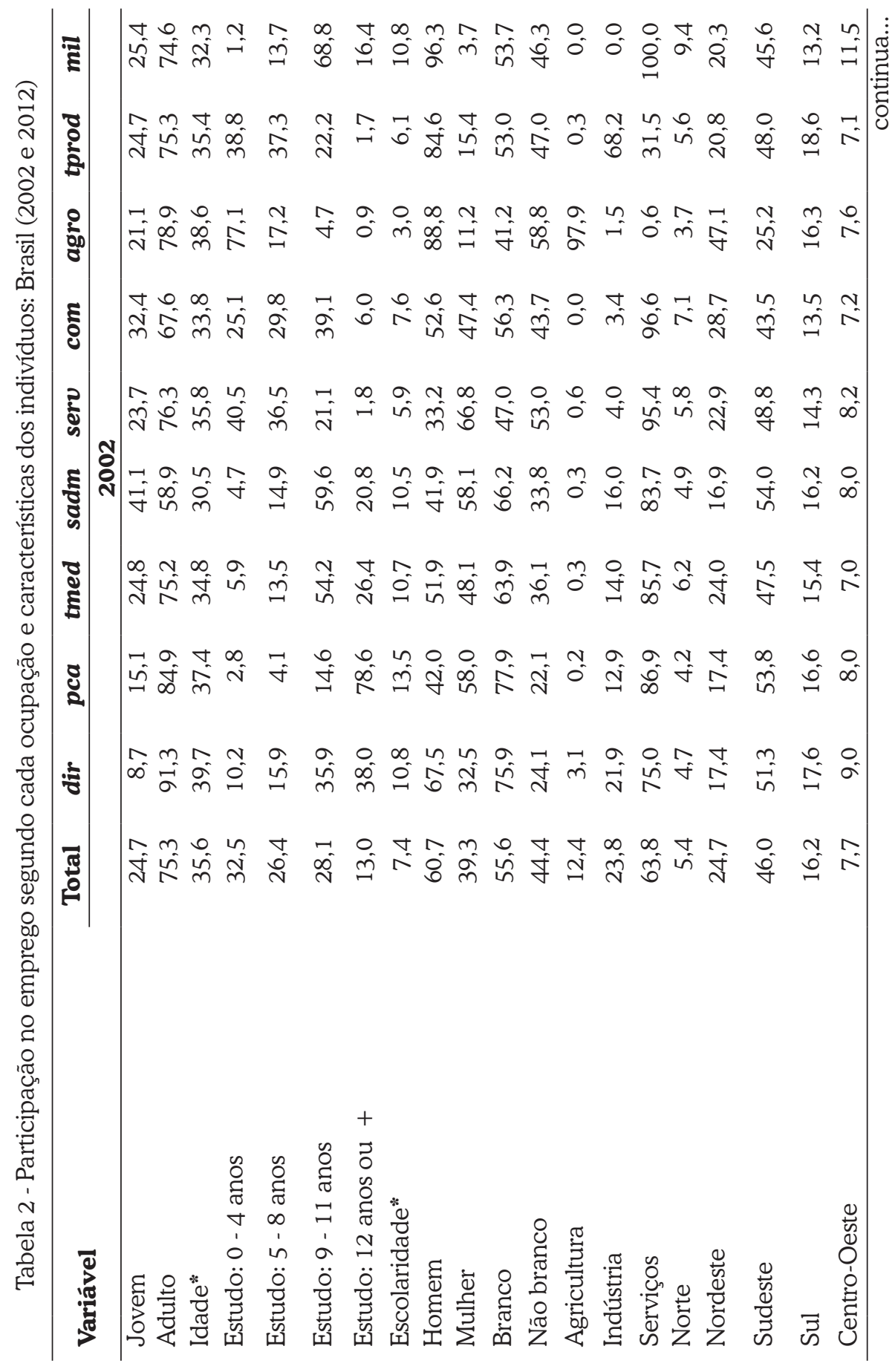




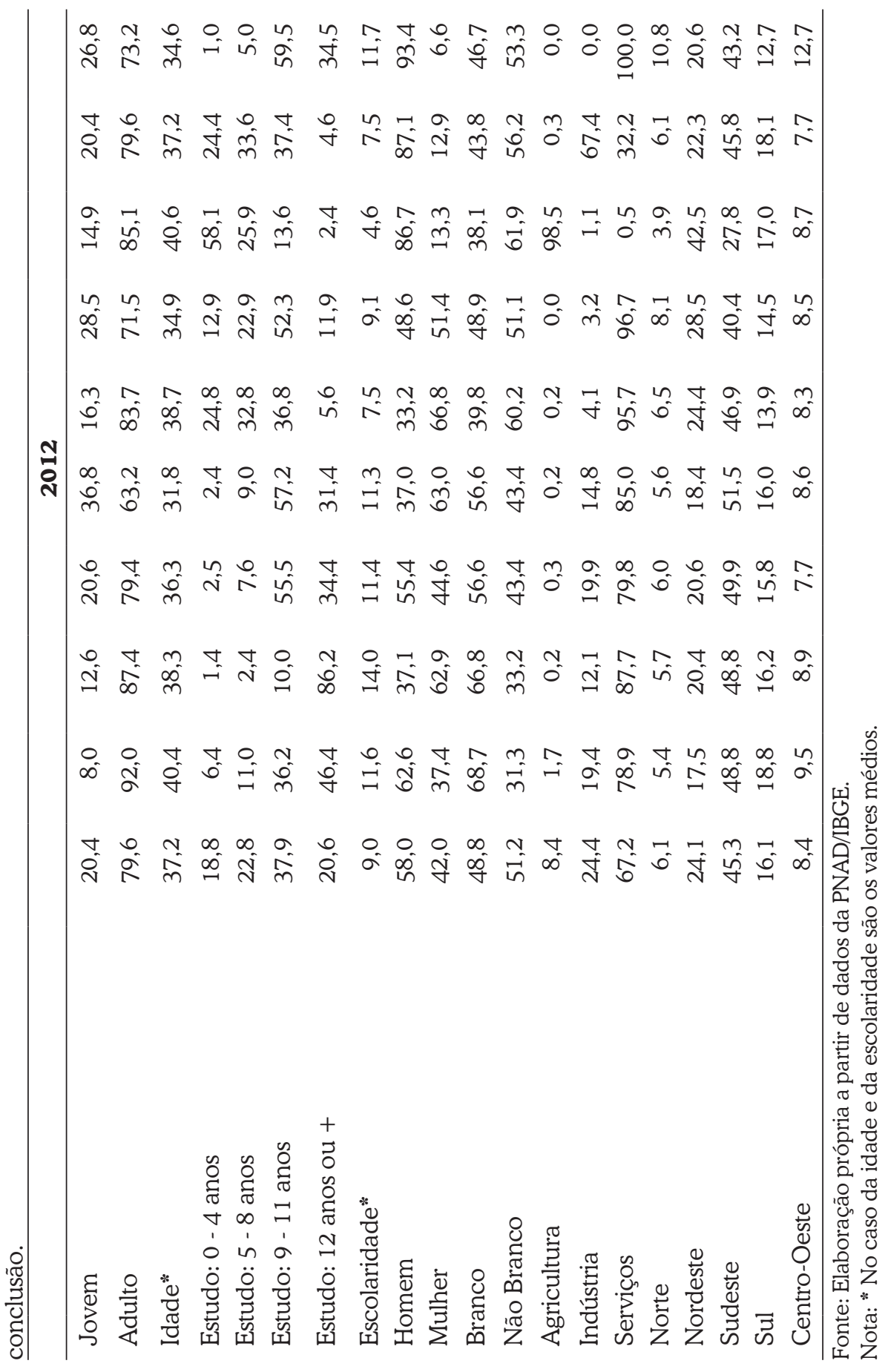


De início, um aspecto interessante a se ressaltar diz respeito à escolaridade dos indivíduos. Pessoas com 12 ou mais anos de estudo tiveram um aumento expressivo, passando de $13,0 \%$ para $20,6 \%$, um comportamento inversamente proporcional à participação dos indivíduos com apenas 0 a 4 anos de estudo, que caiu aproximadamente 13,7 pontos percentuais durante o período analisado. Ademais, a escolaridade média se elevou em mais de 1 ano, passando de 7,4 para 9,0 anos de estudo.

Para jovens e adultos, pode-se observar que, exceto para membros das forças armadas (mil), houve diminuição na participação de indivíduos entre 15 e 25 anos de idade, fato que sugere que o jovem tem optado por continuar estudando em vez de ingressar precocemente no mercado de trabalho. A ocupação que apresentou maior queda na participação entre os jovens foi a de trabalhadores de serviços, com 7,3 pontos percentuais, seguido por trabalhadores dos serviços administrativos, técnicos do ensino médio e trabalhadores da produção.

A ocupação que apresentou o maior aumento na idade média, que pode ser considerada como um indicador da experiência dos indivíduos no mercado de trabalho, foi de trabalhadores dos serviços, com cerca de três anos, seguida por membros das forças armadas, trabalhadores da produção e trabalhadores da agricultura, com cerca de dois anos cada uma. Nota-se o envelhecimento da população economicamente ativa ocupada, com a elevação da idade média, que, em 2002, foi de 35,6 anos e em 2012 de 37,2 anos. Ademais, confirma-se novamente que de uma maneira geral os jovens estão adiando seu ingresso no mercado de trabalho, o que indica que estão investindo mais tempo em capital humano.

De fato, conforme Santos e Gimenez (2015), que analisam a inserção dos jovens no mercado de trabalho brasileiro no período recente, o aumento do número de matriculados no ensino fundamental e médio, além da expansão do ensino médio e superior, contribuíram para a redução do ingresso de jovens no mercado de trabalho. Somado à melhoria no sistema educacional, os autores elencam outros fatores que contribuíram para essa redução, como a melhoria do emprego e da renda das famílias, menor pressão demográfica e a ampliação de políticas públicas, especialmente na área social. ${ }^{8}$

Considerando-se todas as ocupações, tem-se que o mercado de trabalho apresentou aumento dos anos de estudo, não havendo exceção nesse aspecto. Assim, a média da escolaridade dentro das ocupações passou de 8,7 anos, em

8 Entre as políticas públicas implementadas, os autores citam: o Programa Universidade para Todos (Prouni), que concede bolsas de estudo integrais e parciais (50\%) em instituições privadas de ensino superior, e o Financiamento Estudantil (Fies), que financia cursos de graduação para estudantes matriculados em instituições não gratuitas; o Programa Minha Casa, Minha Vida (MCMV), que contribuiu para a proteção das famílias e melhoria de seu bem-estar, e o Programa Bolsa Família (PBF), que é um programa de transferência direta de renda para famílias em situação de pobreza e extrema pobreza, com alguns condicionantes, entre eles a frequência escolar. 
2002, para 9,9 anos em 2012, um comportamento positivo e importante para o país. Outro fato relevante recai no expressivo incremento de 53,3\% no nível de escolaridade dos trabalhadores agrícolas, historicamente com o menor nível educacional, apesar de ainda apresentar a menor escolaridade média, com 4,6 anos em 2012. Segundo Cunha (2008), no período de 1981 até 2005, verifica-se o aumento da escolaridade média na agricultura, embora com média ainda inferior ao do mercado de trabalho brasileiro. Ademais, ainda se pode destacar a redução de mão de obra pouco qualificada nesse setor, como aponta Moraes (2007) sobre os postos de trabalho na agroindústria canavieira, que tem sofrido com o avanço da mecanização da sua colheita, especialmente no estado de São Paulo.

Além disso, para trabalhadores dos serviços, do comércio e da produção, a escolaridade média teve incremento de aproximadamente 1,5 anos de estudo, entre 2002 e 2012. Por outro lado, dirigentes em geral e profissionais das ciências e das artes foram as ocupações que apresentaram o menor aumento, passando de 10,8 anos para 11,6 anos no primeiro caso e de 13,5 para 14 anos, no segundo, o que pode ser justificado por já se encontrarem relativamente com alto nível de escolaridade desde 2002.

No aspecto relacionado à discriminação no mercado de trabalho, um dado interessante na questão do sexo é o aumento da participação da mulher em sete das nove ocupações de 2002 para 2012. Houve aumento de 5,0 pontos percentuais para diretores em geral, 4,9 para profissionais das ciências e das artes, 5,2 para trabalhadores dos serviços administrativos, 4,9 para trabalhadores do comércio, 2,0 para trabalhadores agrícolas e 2,9 para membros das forças armadas. As únicas ocupações que apresentaram queda da participação feminina foram de técnicos de nível médio, com 3,5\%, e trabalhadores da produção, com 2,6\%, números relativamente baixos quando comparados ao das demais categorias. Além disso, no caso dos trabalhadores dos serviços houve manutenção da sua participação relativa.

Desse modo, os resultados têm o comportamento esperado, pois de uma maneira geral as mulheres têm aumentando a sua participação no mercado de trabalho ao longo dos anos, inclusive ganhando espaços outrora dominados por homens, como em cargos de dirigentes, por exemplo, cuja participação no emprego cresceu de 32,5 para 42,0\%, no período. Segundo Leone e Baltar (2008), a segregação da mulher em ocupações além do trabalho doméstico tem diminuído com sua maior participação no mercado de trabalho, ou seja, tem ocorrido redução de restrições em relação às mulheres na ocupação de postos de trabalho com melhor prestígio social.

Outra questão analisada é a segmentação relacionada à cor/raça do indivíduo. De acordo com as informações, a participação dos brancos diminuiu em todos os cargos, inclusive naqueles com os maiores rendimentos, como dirigentes 
e profissionais das ciências e das artes. A ocupação que apresentou a queda mais significativa foi a de profissionais das ciências e das artes, atingindo 11,2 pontos percentuais, seguida por trabalhadores dos serviços administrativos e da produção, com 9,6 e 9,2 respectivamente. O interessante do comportamento apresentado é o fato de indicar uma maior participação dos indivíduos das mais diversas etnias/cor no mercado de trabalho brasileiro, o que pode sinalizar menor discriminação no mercado de trabalho.

Por fim, tem-se a análise das ocupações de acordo com a segmentação do mercado de trabalho, em que são considerados os setores da economia - primário, secundário e terciário - e as regiões geográficas do país. O setor primário, caraterizado pelos trabalhos relacionados à agricultura, absorve quase a totalidade da ocupação "trabalhadores agrícolas", de modo que as outras ocupações possuem porcentagem pouco expressiva nesse setor da economia. De maneira geral, pode-se dizer que as ocupações dentro do primeiro setor mantiveram um comportamento estável durante o período.

Do total de empregados na ocupação "trabalhadores da produção", estão empregados no setor secundário ou industrial 68,2\%, em 2002, e 67,4\% em 2012. Nesse setor ainda se destacam os postos de trabalho ocupados por técnicos do ensino médio, dirigentes em geral, trabalhadores dos serviços administrativos e profissionais das ciências e das artes.

Tem-se ainda o setor terciário, representado pelos serviços, em que há indivíduos empregados em todas as ocupações, com números acima de $75 \%$ tanto em 2002, quanto em 2012, à exceção de trabalhadores agrícolas e trabalhadores da produção, cuja ocupação está diretamente relacionada ao primeiro e segundo setores da economia, respectivamente. Com isso, pode-se aferir que o setor da economia que possui maior relevância na geração de emprego no mercado de trabalho, dada a porcentagem de participação das ocupações, é o setor terciário. Esse fato está de acordo com a mudança estrutural de desenvolvimento de uma economia, de predominância do emprego primeiro no setor agrícola, depois no industrial e, na sequência, no de serviços. No Brasil, conforme Silva, Menezes-Filho e Komatsu (2016), em 2011 os empregos no setor de serviços representavam $63,7 \%$ do total, na indústria, 20,1\% e na agricultura, 16\%. Já, em 1950, esses valores correspondiam a $19,1 \%, 16,4 \%$ e $64,3 \%$, respectivamente.

Partindo para a análise regional, algumas considerações podem ser realizadas. A região Sudeste se mantém como a mais importante na composição do emprego, com redução de 46,0\% para 45,3\% do emprego total, de 2002 para 2012, o que está de acordo com o crescimento econômico nas demais regiões. Em oito ocupações ocorreram reduções na proporção de empregos nessa região, com exceção dos trabalhadores dos serviços administrativos. A região Sul também teve reduções, mas em cinco ocupações, a região Nordeste em duas e as demais em 
apenas uma ocupação, o que se constitui um reflexo do ocorrido na região Sudeste. Portanto, há expansão relativa do emprego nas regiões menos desenvolvidas, por exemplo, como dos profissionais das ciências e das artes, em que se notou queda relativa do emprego apenas nas regiões Sudeste e Sul.

Portanto, no período estudado, o mercado de trabalho passou por algumas transformações. Os trabalhadores estão mais qualificados e mais velhos, tanto mulheres quanto não brancos estão ocupando mais postos de trabalhos. As regiões consideradas mais desenvolvidas, Sudeste e Sul, estão perdendo relativamente emprego, assim como o setor agrícola, em detrimento dos demais.

\section{Evidências sobre os Diferenciais de Rendimentos entre as Ocupações no Brasil}

A desigualdade de rendimentos no Brasil vem diminuindo, o que pode ser constatado com as informações da Tabela 3, para 2002 e 2012, com a redução das medidas de desigualdade, o índice de Gini, Theil $L$ e Theil $T$.

Tabela 3 - Medidas de desigualdade e média do rendimento (R\$): Brasil (2002-2012)

\begin{tabular}{lrrrrrr}
\hline \multirow{2}{*}{ Descrição } & \multicolumn{2}{c}{ Total } & \multicolumn{2}{c}{ Homens } & \multicolumn{2}{c}{ Mulheres } \\
\cline { 2 - 7 } & $\mathbf{2 0 0 2}$ & $\mathbf{2 0 1 2}$ & $\mathbf{2 0 0 2}$ & $\mathbf{2 0 1 2}$ & $\mathbf{2 0 0 2}$ & $\mathbf{2 0 1 2}$ \\
\hline Gini & 0,550 & 0,483 & 0,550 & 0,486 & 0,533 & 0,464 \\
Theil-T & 0,619 & 0,512 & 0,621 & 0,519 & 0,570 & 0,465 \\
Theil-L & 0,551 & 0,421 & 0,545 & 0,418 & 0,522 & 0,397 \\
Rendimento & & & & & & \\
médio & $1.140,38$ & $1.468,22$ & $1.305,24$ & $1.655,32$ & 913,21 & $1.210,02$ \\
Dir & & & & & & \\
Pca & $3.547,21$ & $3.806,68$ & $3.987,16$ & $4.254,53$ & $2.734,73$ & $3.055,83$ \\
Tmed & $3.001,55$ & $3.092,66$ & $4.041,83$ & $4.305,31$ & $2.295,87$ & $2.376,40$ \\
Sadm & $1.547,51$ & $1.934,92$ & $1.919,15$ & $2.268,87$ & $1.177,01$ & $1.520,38$ \\
Serv & $1.066,89$ & $1.227,31$ & $1.224,78$ & $1.411,57$ & 970,11 & $1.119,27$ \\
Com & 572,36 & 811,90 & 784,88 & $1.041,70$ & 474,80 & 697,86 \\
Agro & 807,76 & $1.105,29$ & 996,63 & $1.335,15$ & 614,49 & 887,72 \\
Tprod & 574,34 & 882,83 & 605,34 & 922,16 & 377,56 & 625,40 \\
Mil & 873,40 & $1.204,63$ & 943,95 & $1.263,21$ & 540,21 & 808,71 \\
\hline & $2.107,38$ & $2.785,07$ & $2.118,48$ & $2.750,52$ & $2.355,80$ & $3.276,00$ \\
\hline
\end{tabular}

Fonte: Elaboração própria a partir de dados da PNAD/IBGE. 
O rendimento médio teve crescimento em todas as ocupações, com aumento médio de 28,7\%. Embora esse aumento não tenha sido uniforme entre as ocupações, está de acordo com a redução das desigualdades no mercado de trabalho, uma vez que, de um lado, a ocupação com o menor rendimento médio apresentou o maior aumento e, de outro lado, aquelas com os maiores rendimentos médios obtiveram as menores variações.

Assim, os trabalhadores agrícolas (agro) estão na ocupação responsável pela maior variação positiva, com um aumento de 53,7\% na década, saindo de $R \$ 574,34$ para $R \$ 882,83$, o que contribui para a redução da desigualdade de rendimentos e está de acordo com a redução da proporção de trabalhadores menos qualificados - verificada na análise da seção anterior, que analisou a dinâmica do emprego entre as ocupações. De fato, segundo Maia (2013), a redução do emprego no setor agrícola, devido à mecanização agrícola e ao êxodo rural, contribuiu para a redução da desigualdade de rendimentos, com redução das diferenças de rendimento entre as ocupações e maior proporção de indivíduos mais qualificados. $^{9}$

Ainda entre os maiores aumentos estão os trabalhadores dos serviços (serv), com variação positiva no salário de 41,9\%, seguidos por trabalhadores da produção (tprod), com 37,9\%, trabalhadores do comércio (com), com 36,8\%, e membros das forças armadas (mil), com 32,2\%. Por outro lado, as menores variações ocorreram para os profissionais das ciências e das artes ( $p c a)$, diretores em geral (dir), trabalhadores dos serviços administrativos (sadm) e trabalhadores do ensino médio (tmed).

Com relação ao sexo, em relação às medidas de desigualdade, também se observa queda de 2002 para 2012, tanto para homens quanto para mulheres, em que o nível de desigualdade é menor entre as mulheres. Além disso, fica evidente que as mulheres possuem um menor retorno que os homens, com exceção dos membros das forças armadas e auxiliares, ocupação que, em 2012, representava apenas $6,5 \%$ dos postos de trabalho, conforme a Tabela 2 .

A decomposição da desigualdade, com base nos índices de Theil, pode ser observada na Tabela 4, em que são considerados os atributos ocupação, características pessoais produtivas (escolaridade e idade), características pessoais não produtivas relacionadas à discriminação (sexo e cor) e postos de trabalho (setorial e regional).

9 Foram analisadas as informações da PNAD de 2002 e 2011. 
Tabela 4 - Decomposição da desigualdade de rendimento segundo os índices de Theil: Brasil (2002-2012)

\begin{tabular}{|c|c|c|c|c|c|c|c|c|}
\hline \multirow{3}{*}{$\begin{array}{l}\text { Deter- } \\
\text { minan- } \\
\text { te }\end{array}$} & \multicolumn{4}{|c|}{2002} & \multicolumn{4}{|c|}{2012} \\
\hline & \multicolumn{2}{|c|}{ Theil $L(\alpha=0)$} & \multicolumn{2}{|c|}{ Theil T $(\alpha=1)$} & \multicolumn{2}{|c|}{ Theil L $(\alpha=0)$} & \multicolumn{2}{|c|}{ Theil T $(\alpha=1)$} \\
\hline & Dentro & Entre & Dentro & Entre & Dentro & Entre & Dentro & Entre \\
\hline \multicolumn{9}{|l|}{ Total } \\
\hline $\begin{array}{l}\text { Ocupa- } \\
\text { ção }\end{array}$ & 66,55 & 33,45 & 65,71 & 34,29 & 70,71 & 29,29 & 72,95 & 27,05 \\
\hline $\begin{array}{l}\text { Escola- } \\
\text { ridade }\end{array}$ & 68,94 & 31,06 & 68,05 & 31,95 & 74,65 & 25,35 & 77,21 & 22,79 \\
\hline Idade & 91,59 & 8,41 & 93,61 & 6,39 & 93,19 & 6,81 & 95,15 & 4,85 \\
\hline Sexo & 97,32 & 2,68 & 97,70 & 2,30 & 97,22 & 2,78 & 97,76 & 2,24 \\
\hline Cor & 90,28 & 9,72 & 91,86 & 8,14 & 91,82 & 8,18 & 93,40 & 6,60 \\
\hline Setor & 95,37 & 4,63 & 96,58 & 3,42 & 97,67 & 2,33 & 98,32 & 1,68 \\
\hline Região & 92,99 & 7,01 & 94,45 & 5,55 & 94,99 & 5,01 & 96,20 & 3,80 \\
\hline \multicolumn{9}{|l|}{ Homem } \\
\hline $\begin{array}{l}\text { Ocupa- } \\
\text { ção }\end{array}$ & 65,85 & 34,15 & 64,54 & 35,46 & 70,08 & 29,92 & 71,58 & 28,42 \\
\hline $\begin{array}{l}\text { Escola- } \\
\text { ridade }\end{array}$ & 66,29 & 33,71 & 64,63 & 35,37 & 72,06 & 27,94 & 74,64 & 25,36 \\
\hline Idade & 89,92 & 10,08 & 92,59 & 7,41 & 91,56 & 8,44 & 94,21 & 5,79 \\
\hline Cor & 89,29 & 10,71 & 91,13 & 8,87 & 90,84 & 9,16 & 92,73 & 7,27 \\
\hline Setor & 90,48 & 9,52 & 92,96 & 7,04 & 94,33 & 5,67 & 95,91 & 4,09 \\
\hline Região & 91,49 & 8,51 & 93,42 & 6,58 & 93,76 & 6,24 & 95,40 & 4,60 \\
\hline \multicolumn{9}{|l|}{ Mulher } \\
\hline $\begin{array}{l}\text { Ocupa- } \\
\text { ção }\end{array}$ & 61,99 & 38,01 & 61,43 & 38,57 & 66,94 & 33,06 & 69,34 & 30,66 \\
\hline $\begin{array}{l}\text { Escola- } \\
\text { ridade }\end{array}$ & 61,48 & 38,52 & 61,44 & 38,56 & 68,32 & 31,68 & 71,81 & 28,19 \\
\hline Idade & 94,18 & 5,82 & 95,27 & 4,73 & 95,21 & 4,79 & 96,36 & 3,64 \\
\hline Cor & 90,49 & 9,51 & 91,84 & 8,16 & 91,89 & 8,11 & 93,26 & 6,74 \\
\hline Setor & 97,77 & 2,23 & 98,41 & 1,59 & 98,66 & 1,34 & 99,04 & 0,96 \\
\hline Região & 94,62 & 5,38 & 95,51 & 4,49 & 96,20 & 3,80 & 96,98 & 3,02 \\
\hline
\end{tabular}

Fonte: Elaboração própria a partir de dados da PNAD/IBGE.

Desse modo, por exemplo, tem-se a proporção da desigualdade de rendimento entre as ocupações e dentro de cada ocupação. Inicialmente, nota-se que 
a contribuição da desigualdade entre as ocupações para a desigualdade de rendimentos total apresentou redução no período analisado, acompanhando a tendência da desigualdade total. No caso do índice Theil $L(\alpha=0)$, foi igual a 35,45\%, no ano de 2002, e a 29,29\%, em 2012. Já para o índice Theil T ( $\alpha=1)$, em 2002 a desigualdade entre as ocupações explicava 34,29\% da desigualdade total e 27,0\% no ano de 2012. Ademais, nota-se que a desigualdade entre as ocupações é a que mais contribui para a desigualdade total, considerando as duas medidas de desigualdade, tanto em 2002, quanto em 2012. Em geral, essas modificações também são observadas tanto para homens, quanto para mulheres.

A queda de $12,4 \%$ no poder explicativo da ocupação para a primeira medida, Theil $L$, no período estudado pode estar relacionada ao aumento da renda da camada mais pobre da população durante os anos de 2002 e 2012, capitaneado por trabalhadores agrícolas e trabalhadores dos serviços. Isso faz sentido pelo fato dessa medida ser mais sensível a mudanças na cauda inferior da distribuição ou captar mais as mudanças para a população mais vulnerável. Além disso, a redução de $21,1 \%$ na segunda medida, Theil $T$, sinaliza que há mudanças na cauda superior da distribuição, ou entre os mais ricos, ainda mais profundas. De maneira geral, esses resultados são positivos, pois indicam que as medidas de desigualdade estão diminuindo, ou seja, o país está caminhando para o desenvolvimento econômico e social de fato.

A questão da heterogeneidade, por sua vez, considerando experiência (idade) e escolaridade, assim como os outros grupos analisados, também contribuiu positivamente para a queda da desigualdade. No caso do índice Theil $L$, a idade caiu de $8,41 \%$ para $6,81 \%$ como fator explicativo para a desigualdade de renda, ou seja, a experiência do indivíduo tem se tornado menos relevante para os diferenciais de rendimento, fato que pode ser justificado pela maior idade média entre os trabalhadores e a redução dos mais jovens no mercado de trabalho. $\mathrm{O}$ atributo escolaridade também apresentou queda, passando de 31,06\%, em 2002, para 25,35\%, em 2012: isso se deve ao aumento da escolaridade dos indivíduos nas últimas décadas, de modo que, embora a alta escolaridade ainda seja significativa para diferenciar rendimentos, à medida que há mais indivíduos com alto grau de instrução, menor é seu impacto na desigualdade total.

$\mathrm{Na}$ análise dessa medida de desigualdade para a discriminação, nota-se queda no caso da cor, passando de 9,72\%, em 2002, para 8,18\% em 2012. A variável sexo, embora em 2002 já apresentasse contribuição baixa para explicar os diferenciais de rendimento (2,68\%), em 2012 sofre pequena elevação (2,78\%). ${ }^{10} \mathrm{O}$ inte-

10 A elevação ocorrida no caso do Índice Theil $L$ para sexo pode ser explicada pela redução no índice de 0,551 para 0,421, conforme a Tabela 3, bem maior que a contribuição do sexo de 0,0147 para 0,0117 . Portanto, enquanto em termos absolutos a contribuição bruta reduz para sexo, em termos relativos nota-se elevação. Vale destacar também que, paralelamente, a contribuição bruta calculada pelo índice Theil $T$ tem redução. 
ressante na questão do sexo é que se constitui em um fator com uma das menores contribuições para a explicação da desigualdade total, indicando que a discriminação da mulher no mercado de trabalho está cada vez menor, o que é corroborado pela maior participação da mulher em todas as ocupações, conforme a Tabela 4. Assim, esse aumento, apesar de pequeno, deve ser visto com cautela, pois com a maior participação da mulher no mercado de trabalho se espera continuidade na sua queda. Portanto, esse resultado pode indicar certo esgotamento no ritmo da redução das desigualdades de sexo.

Com relação aos demais fatores estudados, para a desigualdade entre grupos no índice Theil $L(\alpha=0)$, quando se analisa a questão das características dos postos de trabalho, tem-se que a região geográfica apresentou variação negativa de 2,3 pontos percentuais na proporção explicada da desigualdade e que o setor da economia - indústria, serviços e agricultura -, por sua vez, apresentou queda similar à região, com variação de 2,0 pontos percentuais.

Com relação ao gênero, tanto para homens quanto para mulheres, se observam as mesmas tendências que para o Brasil, em que se nota queda na desigualdade entre grupos e a ocupação aparece como um dos principais determinantes da desigualdade total, embora atrás da escolaridade em alguns casos. Para a ocupação, o nível de desigualdade é maior entre os homens que entre as mulheres.

Neste estudo dos diferenciais de rendimento segundo a ocupação dos indivíduos, além da análise univariada anterior, também é considerada a seguir uma abordagem multivariada, que permite controlar o efeito de cada variável incluída no modelo empírico proposto, buscando isolar o impacto das ocupações nos diferenciais de rendimento dos demais determinantes analisados. Nessa perspectiva, foi realizada uma análise de regressão, cujos resultados são apresentados na Tabela 5. 
Tabela 5 - Estimativas das equações de rendimentos: Brasil (2002-2012)

\begin{tabular}{|c|c|c|c|c|}
\hline \multirow{2}{*}{ Variável } & \multicolumn{2}{|c|}{2002} & \multicolumn{2}{|c|}{2012} \\
\hline & Modelo 1 & Modelo 2 & Modelo 1 & Modelo 2 \\
\hline Dirigentes em geral & $1,924 * * *$ & $0,885 * * *$ & $1,621 * * *$ & $0,964 * * *$ \\
\hline $\begin{array}{l}\text { Profissionais das ciências e das } \\
\text { artes }\end{array}$ & $1,714 * * *$ & $0,543 * * *$ & $1,387 * *$ & $0,684 * * *$ \\
\hline Técnicos de nível médio & $1,138 * * *$ & $0,356 * * *$ & $0,998 * * *$ & $0,493 * * *$ \\
\hline $\begin{array}{l}\text { Trabalhadores de serviços } \\
\text { administrativos }\end{array}$ & $0,896 * * *$ & $0,260 * * *$ & $0,697 * * *$ & $0,360 * * *$ \\
\hline Trabalhadores dos serviços & $0,256 * * *$ & $-0,034$ & $0,258 * * *$ & $0,112 * * *$ \\
\hline $\begin{array}{l}\text { Vendedores e prestadores de } \\
\text { serviços do comércio }\end{array}$ & $0,484 * * *$ & $0,041^{*}$ & $0,456 * * *$ & $0,228 * * *$ \\
\hline Trabalhadores da produção & $0,668 * * *$ & $0,125 * *$ & $0,663 * *$ & $0,319 * * *$ \\
\hline $\begin{array}{l}\text { Membros das forças armadas e } \\
\text { auxiliares }\end{array}$ & $1,659 * * *$ & $0,689 * * *$ & $1,501 * * *$ & $0,846 * * *$ \\
\hline Idade & & $0,091 * * *$ & & $0,068 * * *$ \\
\hline Idade ao quadrado & & $-0,001 * * *$ & & $-0,001 * * *$ \\
\hline Ensino fundamental & & $0,268 * * *$ & & $0,229 * * *$ \\
\hline Ensino médio & & $0,541 * * *$ & & $0,436 * * *$ \\
\hline Graduação ou mais & & $1,081 * *$ & & $0,828 * *$ \\
\hline Homem & & $0,513 * *$ & & $0,425 * *$ \\
\hline Branco & & $0,141 * * *$ & & $0,124 * * *$ \\
\hline Setor industrial & & $0,277 * * *$ & & $0,142 * * *$ \\
\hline Setor de serviços & & $0,324 * * *$ & & $0,166 * * *$ \\
\hline Nordeste & & $-0,311 * * *$ & & $-0,273 * * *$ \\
\hline Sudeste & & $0,192 * *$ & & $0,172 * * *$ \\
\hline Sul & & $0,119 * * *$ & & $0,162 * * *$ \\
\hline
\end{tabular}


conclusão.

\begin{tabular}{lcccc}
\hline \multirow{2}{*}{ Variável } & \multicolumn{2}{c}{2002} & \multicolumn{2}{c}{2012} \\
\cline { 2 - 5 } & Modelo I & Modelo 2 & Modelo I & Modelo 2 \\
\hline Centro-Oeste & & $0,165^{* * *}$ & & $0,235^{* * *}$ \\
Constante & $5,802 * * *$ & $3,386 * * *$ & $6,216 * * *$ & $4,190 * * *$ \\
Número de observações & 145.682 & 145.682 & 160.954 & 160.954 \\
$\mathrm{R}^{2}$ & 0,286 & 0,5212 & 0,245 & 0,4084 \\
\hline
\end{tabular}

Fonte: Elaboração própria a partir de dados da PNAD/IBGE.

Nota: * Estatisticamente significante a 10\%; * estatisticamente significante a 5\%; * * estatisticamente significante a $1 \%$.

Para cada ano analisado foram estimados dois modelos, o primeiro (modelo 1) incluindo apenas as variáveis binárias para distinguir as ocupações, buscando captar o total dos diferenciais de rendimento em cada ocupação, e o segundo (modelo 2) incluindo alguns controles, sendo idade, idade ao quadrado, escolaridade, sexo, cor, setor e região, a fim de se verificar se os diferenciais de rendimento devido às ocupações se mantinham. Novamente, destaca-se que os grupos omitidos na análise (e que são utilizados como referência) são os trabalhadores agrícolas, indivíduos com 0 a 4 anos de estudo, mulher, não brancos, setor agrícola e região Norte.

Assim, tem-se que o ajuste do modelo, a partir do coeficiente de determinação $\left(R^{2}\right)$, foi de 0,286 , para o modelo 1 , e de 0,5212 , para o modelo 2 , no ano de 2002. Para 2012, esses valores foram de 0,245 e de 0,4084, respectivamente. Os resultados estão de acordo com o esperado em análise de dados de corte temporal e microdados, conforme Greene (2012). ${ }^{11}$ Ademais, os coeficientes estimados se mostraram estatisticamente significativos a um nível de 1\%, a exceção dos trabalhadores dos serviços e trabalhadores do comércio em 2002.

A análise dos diferenciais de rendimentos considerando as ocupações é ilustrada nas Figuras 1a e 1b.

11 Para mais detalhes, ver Greene (2012, p. 85). 
Figura 1 - Diferenciais de rendimentos sem e com controles, considerando o total para homens e mulheres: Brasil (2002-2012)

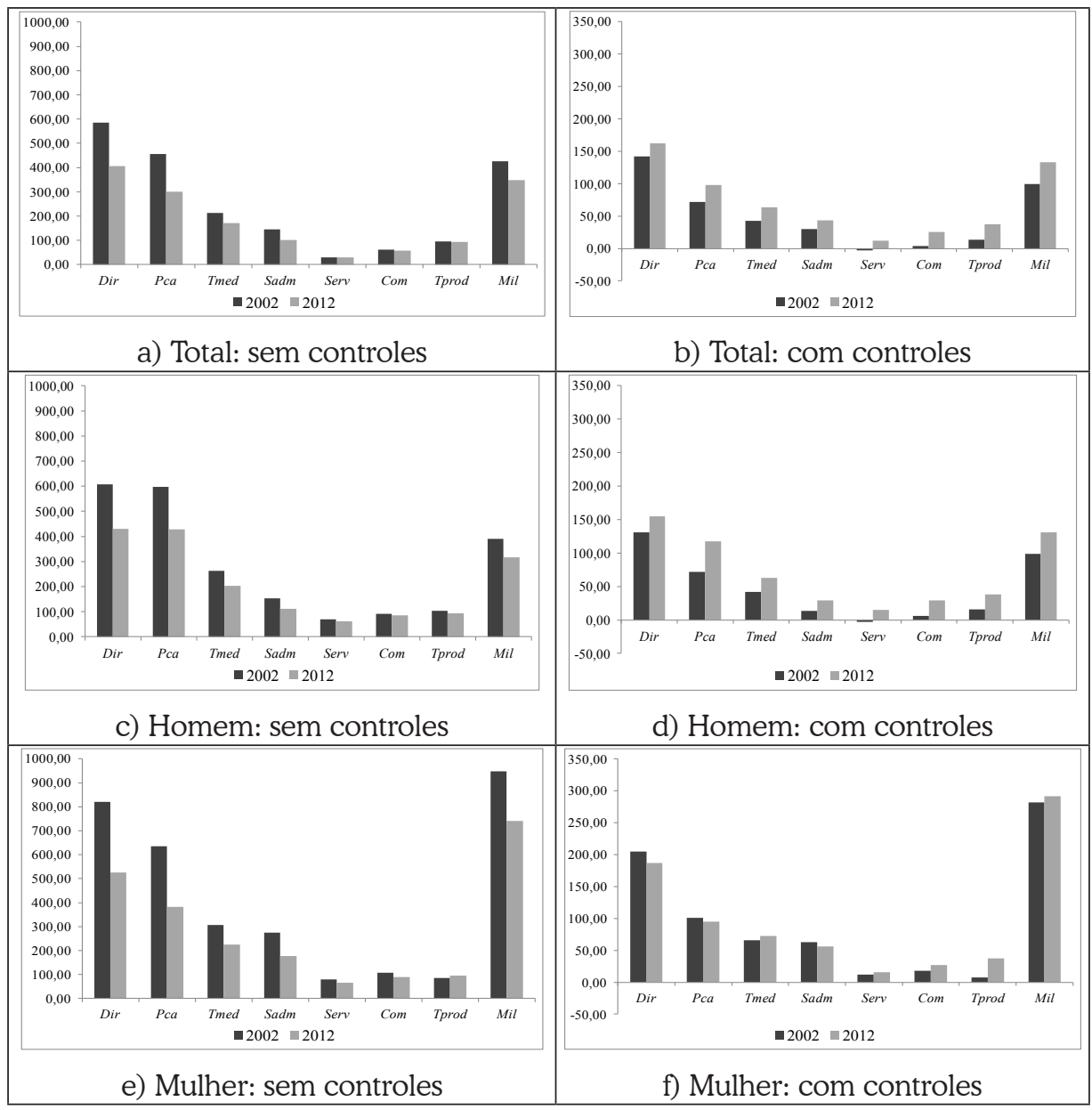

Fonte: Elaboração própria a partir de dados da PNAD/IBGE.

Primeiramente, se apresentam os diferenciais de rendimento das ocupações em relação à variável ocupacional omitida (trabalhadores agrícolas), sem controle, para os dois anos analisados, ou seja, referente ao modelo 1. A interpretação dos resultados é realizada em termos percentuais no caso das variáveis binárias, que fornece o prêmio de rendimento em relação à categoria omitida, ou seja, os diferencias de rendimentos. ${ }^{12}$ Assim, em 2002, a ocupação que apresenta a maior

12 Os prêmios de rendimentos são obtidos a partir dos coeficientes estimados desta forma:

$$
\left(e^{\hat{\beta}_{i}}-1\right) \times 100 \text {. }
$$


variação em relação aos trabalhadores agrícolas é a de dirigentes em geral, atingindo um salário/hora maior de 584,7\%, seguido por profissionais das ciências e das artes com 455,0\%. Verifica-se que, de maneira geral, todas as ocupações apresentaram diferenciais positivos em relação aos trabalhadores agrícolas.

Os resultados de 2012 possuem comportamento semelhante ao ano de 2002, embora se note, em geral, redução dos diferenciais de rendimentos. Nesse caso, novamente a ocupação que melhor remunera em relação à variável omitida é a dos dirigentes em geral, com um diferencial de $406,1 \%$ e profissionais das ciências e das artes vêm na sequência, com 300,2\%. Portanto, todas as ocupações apresentaram resultados positivos em relação à variável omitida no período analisado. Na comparação entre os dois anos, há queda substancial nos diferenciais de rendimentos, sendo que os profissionais das ciências e das artes apresentam a maior queda, seguido por dirigentes em geral e trabalhadores de serviços administrativos.

Por sua vez, na Figura $1 b$ estão os diferenciais de rendimentos de cada ocupação quando é feito o controle por idade, idade ao quadrado, escolaridade, sexo, cor, região e setor de atividade. Um comportamento diferente do apresentado na Figura 1a pode ser visto quando são incluídos os controles: comparando $2002 \mathrm{e}$ 2012, tem-se que os diferenciais de rendimentos entre as ocupações aumentaram em relação à categoria omitida, os trabalhadores agrícolas. Uma explicação para esse fato pode ser atribuída ao aumento do capital humano entre os trabalhadores, especialmente à inclusão da escolaridade no modelo 2 , indicando que a maior parte da queda da desigualdade pode ser devido à elevação do nível de escolaridade. Por exemplo, os trabalhadores agrícolas (variável omitida) são os indivíduos que possuem menor tempo de estudo em toda amostra, considerando-se o resultado da Tabela 1, mas que tiveram aumento significativo nos anos de escolaridade. Assim, quando se controlam os efeitos da escolaridade, incluindo variáveis binárias referentes aos níveis de escolaridade, os diferenciais de ocupação aumentam, pois as variáveis incluídas de escolaridade passam a captar a redução dos diferenciais de rendimento devido à escolaridade. Portanto, esses resultados evidenciam que entre os fatores que explicam a redução da desigualdade dos rendimentos entre as ocupações, observada através das medidas de desigualdade e do modelo 1 de regressão, está a redução das desigualdades educacionais no país.

A partir da Tabela 5 ainda é possível notar que os dirigentes se confirmam como a ocupação que ostenta o maior rendimento, com diferenciais iguais a 142,3\%, em 2002, e 162,2\% em 2012. Profissionais das ciências e das artes caem para terceiro lugar em 2012 , com $98,2 \%$ de prêmio de rendimento, com sua posição substituída por membros das forças armadas (133,1\%). Ademais, à exceção de trabalhadores dos serviços, que, em 2002, apresentaram uma taxa negativa de $3,3 \%$, todos os diferenciais estimados com a inclusão de controles foram positivos em relação à variável omitida. 
Na Figura 1, são observados ainda os diferenciais de rendimento em relação às ocupações para homens e mulheres, cujas regressões foram estimadas novamente para cada sexo. O comportamento desses diferenciais se assemelha mais com aqueles observados para a população ocupada total, o que se justifica pelo fato de representarem a sua maior parcela. No caso das mulheres, as estimativas dos diferenciais são maiores em algumas ocupações: uma explicação seria o fato de que seus rendimentos medianos captados no intercepto sejam menores. ${ }^{13}$ Destaca-se o diferencial positivo dos membros das forças armadas e auxiliares que está de acordo com a análise descritiva da Tabela 3.

Em geral, a Figura 1 evidencia que a explicação para a queda dos diferenciais de rendimento de 2002 para 2012 não se deve ao fato do mercado de trabalho estar remunerando de forma mais homogênea as ocupações, mas sim a outros fatores, como pelo fato de os indivíduos estarem mais qualificados. Quando são analisados outros fatores, o nível de desigualdade entre as ocupações diminui, por exemplo, da Figura 1a para a 1b. Não obstante, há diferenciais compensatórios, apesar de menores após se retirar o efeito de outros determinantes, que ainda são estatisticamente significativos e aumentam no período.

Além das ocupações, a partir dos resultados da Tabela 5 pode-se também verificar se há diferenciais de rendimentos em relação aos demais determinantes. No caso da idade, verifica-se queda nos diferenciais de rendimentos, sendo que, em 2002, um ano a mais na idade representa elevação no rendimento esperado de 0,091 e, em 2012, esse número cai para 0,068. As estimativas para a escolaridade, por sua vez, estão de acordo com o esperado tanto para 2002, quanto para 2012, de modo que, quanto maior o tempo de estudo, maiores são os rendimentos. No entanto, quando analisada a variação da escolaridade entre os anos e sua importância para a explicação dos rendimentos, assim como a idade, nota-se queda nos prêmios de rendimento.

Estimou-se um rendimento mediano para homens maior do que o das mulheres em $67,0 \%$, em 2002, e em 52,9\% em 2012. Os resultados indicam que o país ainda sofre com discriminação por sexo e que em uma década houve queda nesse número. Porém, considerando um leque de 30 anos, tem-se que em meados dos anos 1980 o diferencial entre os sexos era de $51,3 \%$, de acordo com os resultados obtidos a partir da pesquisa de Flori (2007), que tem como foco as ocupações das áreas urbanas e metropolitanas brasileiras. Desse modo, há uma melhora substancial na desigualdade de rendimentos por sexo. Essa queda nos diferenciais de rendimentos também pode ser observada entre brancos e não brancos, para os quais os diferenciais estimados eram superiores para os brancos em 15,1\%, em

13 No caso dos homens, o intercepto do modelo sem controles foi igual a 5,87 e com controles, igual a 3,73, e para as mulheres se tem, respectivamente, 5,31 e 3,61. 
2002, e em 13,2\%, em 2012, sugerindo que ainda há discriminação por cor, mas está em declínio.

Comparado ao setor primário da economia, é observado que o setor que melhor remunera é o de serviços. Em 2002, os diferencias de rendimentos do setor de serviços foram $38,2 \%$ maior do que o do setor agrícola; em 2012, esse número caiu para $18,0 \%$. O setor industrial, por sua vez, também apresentou redução em seus diferenciais de rendimentos, passando de 32,0\%, em 2002, para 15,2\% em 2012. Na análise regional, a região Nordeste possui diferencial negativo em relação à Norte. Por outro lado, nas outras regiões se observa diferencial positivo, sendo a Sudeste a região com a melhor remuneração nos dois períodos analisados.

Por fim, a Tabela 6 traz a contribuição bruta (CB) e a contribuição marginal (CM) dos determinantes da desigualdade da distribuição de salários para 2002 e 2012, a primeira medida obtida a partir do índice de Theil $L$ e a segunda da análise de regressão com os controles. 


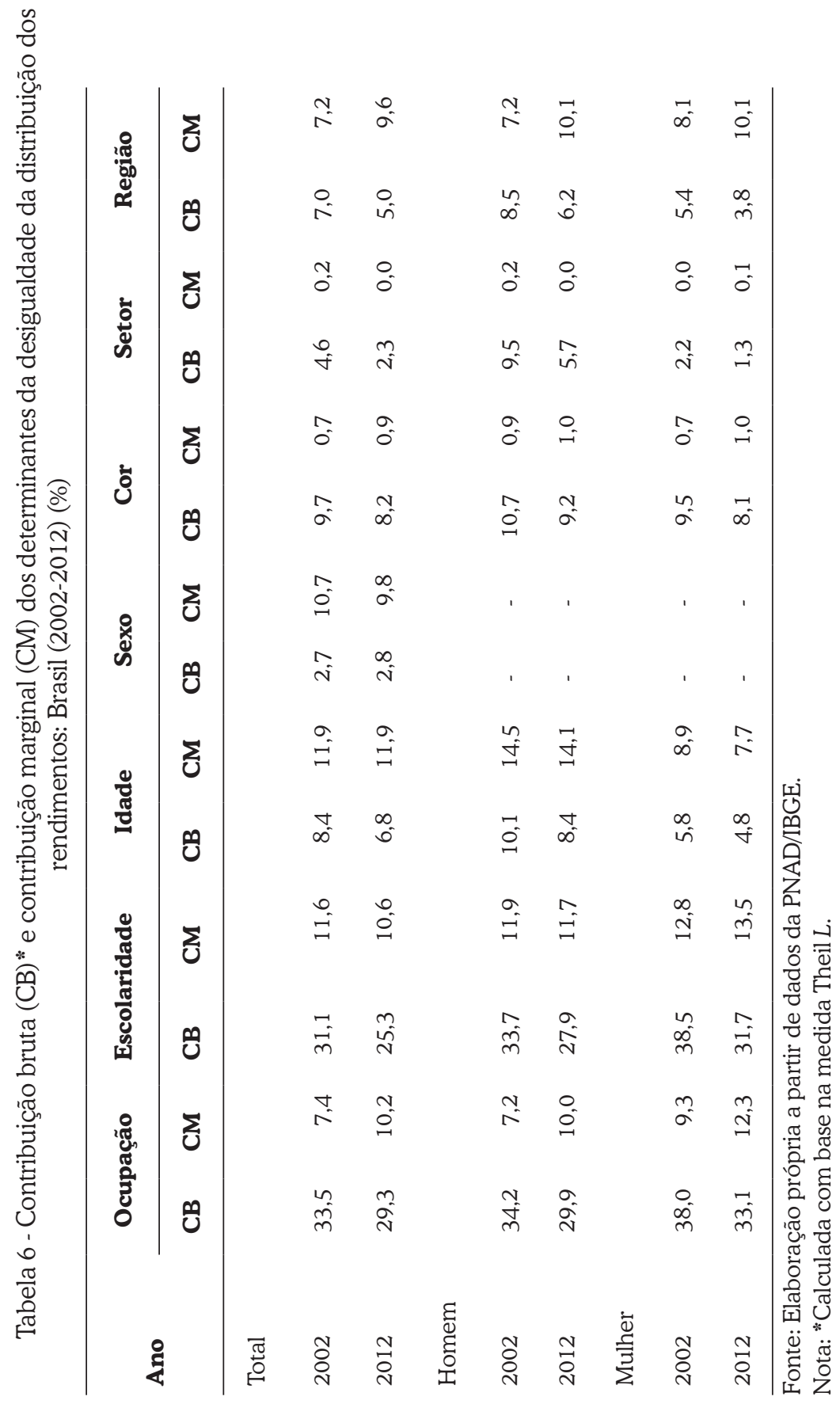


Para o período analisado, ocupação e idade correspondem aos fatores mais relevantes para explicar a desigualdade, sendo que a primeira se sobressai na $\mathrm{CB}$, com 33,5\%, em 2002, e 29,3\%, em 2012, e a segunda, na CM, com 11,9\% nos dois anos. A escolaridade também se destaca, ficando na segunda posição nos dois indicadores.

A ocupação e a educação foram os determinantes com as maiores contribuições para a queda da desigualdade de acordo com a CB, apesar da maioria dos fatores apresentarem queda. Ademais, de acordo com a CM, apenas educação, sexo e setor tiveram redução de 2002 para 2012, enquanto idade manteve seu nível e os demais fatores - ocupação, cor e região - aumentaram sua CM. Assim, por exemplo, esse comportamento sugere que o país, no âmbito da ocupação, está apresentando um rendimento menos discrepante e, na questão da escolaridade, que a política de oferta educacional está avançando. Nota-se que a CM busca captar o efeito individual de cada determinante, controlando o efeito dos demais incluídos na análise, o que justifica seus valores ficarem abaixo do observado na CB.

Por outro lado, as variáveis que apresentaram maior CM foram ocupação, região e cor. Esse fato, que a princípio parece contraditório, pois, enquanto na $\mathrm{CB}$ os determinantes apresentaram queda e na CM para alguns se verificou aumento, pode ser explicado conforme Ramos (2007, p. 290): “[...] esse comportamento distinto se deve, em grande medida, à escolaridade, que é maior entre brancos e amarelos, que têm maiores rendimentos, e também maior entre as mulheres, apesar de elas obterem ganhos laborais menores que os homens." No caso do gênero, os resultados são similares, embora no caso das mulheres se observa resultados mais elevados também para a educação. Portanto, de maneira geral, considerando-se ocupação, região, setor, cor, sexo, idade e escolaridade, os resultados das regressões, da decomposição de desigualdade de renda e da CB e CM se complementam e se confirmam.

Esse fato pode ser melhor compreendido a partir da Figura 1, em que estão apresentados os diferenciais de rendimentos sem alguns controles. Na Figura 1a, estão os diferenciais de rendimentos sem aqueles controles que apresentaram redução na sua CM, quais sejam educação, idade e setor de atividade. Assim, nota-se que, sem esses controles, os diferenciais de rendimentos se reduzem de 2002 para 2012, sugerindo que as ocupações estão sendo remuneradas de forma mais homogênea.

Ao se comparar o resultado da regressão para ocupação, quando não há controle, com o resultado da $\mathrm{CB}$, constata-se que ambos apresentam queda na desigualdade. Por outro lado, quando se observam os resultados das estimativas com os controles, que considera o poder de explicação de uma variável adicionado a um modelo com as demais variáveis já incluídas, nota-se que os diferenciais de rendimento das ocupações aumentam. Seguindo a explicação anterior, isso pode 
ser interpretado por causa da melhoria no nível educacional entre as ocupações, especialmente naquelas com mais baixa remuneração, como entre os trabalhos agrícolas, que também têm reduzido sua participação no emprego. Esse processo está de acordo com o desenvolvimento econômico já ocorrido nos países desenvolvidos. Conforme Autor (2014b), nos Estados Unidos, enquanto, em 1900, 40\% dos empregos estavam no setor agrícola, em 2010 esse percentual se reduziu para $2 \%$, associado com a mecanização e aumento da produtividade.

Assim, foi possível verificar uma tendência de redução mais acentuada nos maiores rendimentos, o que corrobora trabalhos anteriores como de Maia e Quadros (2010) e Maia (2013). Neste último trabalho é realizada uma decomposição da desigualdade de rendimentos para o Brasil, com base no índice $T$ de Theil, verificando redução nos rendimentos dos executivos, administradores e gerentes, que estão entre os mais qualificados, o que representou a contribuição mais importante para a redução da desigualdade dos rendimentos do país de 2002 para 2012 Também com base no índice $T$ de Theil, Ramos (2007) observa um papel relevante da educação para a queda da desigualdade de rendimentos no Brasil de 2001 para 2005.

Salienta-se que, no período do presente estudo, de 2002 para 2012, a economia brasileira apresentou crescimento positivo, apesar de modesto, quando comparada a outros países em desenvolvimento. Entre os impactos no mercado de trabalho se destacam o aumento da formalidade e a queda no desemprego. Paralelamente, se observa melhoria na qualificação dos indivíduos, o que tem contribuído para a redução das desigualdades.

Com isso, a incorporação de novas tecnologias e o aumento da qualificação no mercado de trabalho brasileiro tem contribuído para a redução da desigualdade de rendimento, diferente do que vem ocorrendo nos países mais desenvolvidos, como evidenciam Goldin e Katz (2009), Autor (2014a) e Coelli e Borland (2016), embora, como esses autores advertem, as mudanças na estrutura de ocupações podem também gerar mais desigualdade, fato verificado neste trabalho a partir da decomposição da desigualdade de rendimentos utilizando a CM, ou seja, quando as demais variáveis são controladas.

Assim, apesar da queda observada entre os diferenciais de rendimentos entre as ocupações no país, evidenciada na $\mathrm{CB}$ e na regressão sem controles, a regressão com os controles sugere que essa redução decorre de outros fatores, tais como daqueles relacionados ao capital humano do indivíduo, como a educação, e aos diferenciais de sexo e intersetoriais. Nessa perspectiva, e corroborando as evidências internacionais, quando os efeitos dos demais determinantes são retirados ou controlados, ainda há diferenciais compensatórios de rendimento no Brasil, os quais aumentam de 2002 para 2012, tanto para os homens, quanto para as mulheres. 


\section{Considerações Finais}

O objetivo deste trabalho foi discutir a desigualdade de rendimentos entre as diversas ocupações da CBO, de 2002 para 2012, de modo a identificar a influência dessa estrutura nos rendimentos e emprego no mercado de trabalho brasileiro. Inicialmente, observou-se que os profissionais das ciências e das artes estão na ocupação com a maior variação positiva no emprego nesse período, a qual se caracteriza pelo mais alto nível educacional. Apesar disso, a maior parcela da população ocupada do país é composta por indivíduos com ensino fundamental e médio, em que se destacam as seguintes ocupações: trabalhadores da produção e trabalhadores dos serviços.

Um aspecto positivo observado para o país foi o aumento da escolaridade em todas as ocupações, especialmente entre os trabalhadores agrícolas, apesar de ainda se manterem com o menor nível educacional. Na composição dos postos de trabalho se verificou também redução no setor agrícola e expansão nos demais setores.

O rendimento médio se elevou em todas as ocupações paralelamente à redução da sua dispersão entre as ocupações. Por exemplo, a ocupação com a menor remuneração, os trabalhadores agrícolas, recebeu o maior incremento relativo, e, de outro lado, aqueles com os maiores rendimentos médios receberam o menor aumento, como os profissionais das ciências e artes e os dirigentes.

Esses resultados foram confirmados pela análise das medidas de desigualdade, em que se verificou a importância das ocupações na explicação da desigualdade existente na distribuição dos rendimentos. Por sua vez, também foi estimado um modelo de regressão a fim de se complementar essas análises, em que, quando foram incluídas apenas as ocupações como variáveis explicativas dos rendimentos, ou seja, nas regressões sem controles, foi possível corroborar os resultados anteriores, que indicaram queda nos diferenciais de rendimentos entre as ocupações de 2002 para 2012.

Contudo, quando os demais controles foram incluídos, observou-se que os diferenciais de rendimento atribuídos apenas às ocupações são menores e aumentaram no período. Assim, nesta análise multivariada se evidenciou que os determinantes que apresentaram redução no período foram escolaridade, sexo e setor de atividade. Portanto, os resultados desta pesquisa indicam que a queda da desigualdade entre as ocupações se deve à maior homogeneidade em relação ao capital humano de cada indivíduo, seu nível educacional, bem como aos menores diferenciais de rendimentos de sexo e intersetoriais no mercado de trabalho brasileiro. Assim, quando se comparam indivíduos com a mesma escolaridade, sexo e setor de atividade, ocorre elevação dos diferenciais de rendimentos entre as ocupações no período recente, o que está de acordo com a literatura internacional. 
Esses resultados podem parecer contraditórios, mas são apenas complementares, ou seja, sugerem que a desigualdade de rendimentos entre as ocupações está reduzindo-se em geral devido à menor disparidade de remuneração nos demais determinantes com a escolaridade, o gênero e o setor de atividade de cada indivíduo.

Foi possível, ainda, observar também que a participação das mulheres no mercado de trabalho vem aumentando na maior parte das ocupações estudadas, especialmente naquelas que requerem maior qualificação: seus rendimentos médios estão se aproximando dos obtidos pelos homens, ou seja, os diferenciais de rendimentos de gênero estão menores. Apesar de que em geral a desigualdade entre as mulheres é menor, no caso específico das ocupações observaram-se alguns diferenciais maiores que os estimados entre os homens, como no caso dos dirigentes.

Portanto, em geral, o mercado de trabalho brasileiro ficou mais qualificado, com indivíduos com mais anos de escolaridade, maior participação feminina com menor diferencial de rendimento entre homens e mulheres e entre os setores da economia, o que contribuiu para redução das desigualdades no país, notadamente entre as ocupações, que ainda geram diferenciais compensatórios significativos. De fato, a estrutura de ocupações se constitui ainda no determinante mais significativo para a desigualdade de rendimentos no Brasil e é mais relevante para as mulheres do que para os homens, ou seja, há maior heterogeneidade de rendimentos entre elas devido à estrutura de ocupações.

\section{Referências}

ACEMOGLU, D.; AUTOR, D. Skills, Tasks and Technologies: Implications for Employment and Earnings. Cambridge, MA: National Bureau of Economic Research, 2010. (NBER Working Paper, n. 16082).

AUTOR, D. H. Polanyi's paradox and the shape of employment growth. Cambridge, MA: National Bureau of Economic Research, 2014a. (NBER Working Paper, n. 20485).

ience, v. 344, n. 6186, p. 843-851, 2014 b.

BECKER, J. Investment in human capital: a theoretical analysis. The Journal of Political Economy, v. 70, n. 5, p. 9-49, 1962.

BORJAS, G. Economia do trabalho. 5. ed. Porto Alegre, AMGH, 2012.

BRUSCHINI, C.; LOMBARDI, M. R. O trabalho da mulher brasileira nos primeiros anos da década de noventa. In: ENCONTRO NACIONAL DE ESTUDOS POPULACIONAIS, 10., 1996, Belo Horizonte. Anais... Belo Horizonte: Abep, 1996.

COELLI, M.; BORLAND, J. Job polarisation and earnings inequality in Australia. Economic Record, v. 92, n. 296, p. 1-27, 2016. 
COMIN, A. Desenvolvimento econômico e desigualdades no Brasil: 1960-2010. In: ARRETCHE, M. (Org.). Trajetórias das desigualdades: como o Brasil mudou nos últimos cinquenta anos. São Paulo: Editora Unesp, 2015. p. 367-394.

CORSEUIL, C. H.; FOGUEL, M. N. Uma sugestão de deflatores para rendas obtidas a partir de algumas pesquisas domiciliares do IBGE. Rio de Janeiro: Ipea, 2002. (Texto para discussão, n. 894).

CUNHA, M. S. Os empregados da agricultura brasileira: diferenciais e determinantes salariais. Revista de Economia e Sociologia Rural, v. 46, n. 3, p. 597-621, 2008.

FLORI, P. M. Polarização ocupacional: entendendo o papel da ocupação no mercado de trabalho brasileiro. 2007. 102 f. Tese (Doutorado em Economia) - Faculdade de Economia, Administração e Contabilidade, Universidade Estadual de São Paulo, São Paulo, 2007.

FLORI, P. M.; MENEZES FILHO, N. A. Mobilidade entre ocupações e efeitos salariais. In: ENCONTRO NACIONAL DE ECONOMIA, 36., 2008, Salvador. Anais ... Salvador: Anpec, 2008.

GOLDIN, C.; KATZ, L. F. The race between education and technology: the evolution of U.S. educational wage differentials, 1890 to 2005. Cambridge, MA: NBER, July 2009. (NBER Working Paper, n. 12984).

GREENE, W. H. Econometric analysis. 7. ed. Boston: Pearson, 2012.

HOFFMANN, R. Distribuição de renda: medidas de desigualdade e pobreza. São Paulo: Edusp, 1998.

. Mensuração da desigualdade e da pobreza no Brasil. In: HENRIQUES, R. (Org.). Desigualdade e pobreza no Brasil. Rio de Janeiro: Ipea, 2000, v. 1, p. 81-107.

KATZ, L. F.; AUTOR, D. Changes in the wage structure and earnings inequality. In: ASHENFELTER, O.; CARD., D. (Ed.). Handbook of labor economics. Amsterdam: Elsevier, 1999. v. 3. p. 1463-1555.

KUBRUSLY, L. S. Mulheres e homens no mercado de trabalho brasileiro. Rio de Janeiro: IE/ UFRJ, 2015. (Texto para discussão, n. 18).

LEONE, E. T.; BALTAR, P. A mulher na recuperação recente do mercado de trabalho brasileiro. Revista Brasileira de Estudos da População, São Paulo, v. 25, n. 2, p. 233-249, jul.dez. 2008.

MACHADO, A. F.; OLIVEIRA, A. M.; WAJNMAN, S. Sexo frágil? Evidências sobre a inserção da mulher no mercado de trabalho brasileiro. São Paulo: Gelre, 2005. (Coletânea Gelre Série Estudos do Trabalho).

MAIA, A. G. Estrutura de ocupações e distribuição de rendimentos: uma análise da experiência brasileira nos anos 2000. Revista de Economia Contemporânea, Rio de Janeiro, v. 17, n. 2, p. 276-301, maio-ago. 2013. 
MAIA, A. G.; QUADROS, W. J. Dinâmica das ocupações no Brasil em duas décadas de baixo crescimento econômico. Revista ABET, v. 9, n. 2, p. 143-161, 2010.

MILLS, W. A nova classe média. Rio de Janeiro: Zahar Editores, 1979.

MINCER, J. Schooling, experience and earnings. New York: National Bureau of Economic Research; Columbia University, 1974.

MOORKHERJEE, D.; SHORROCKS, A. A decomposition analysis of trend in UK income inequality. The Economic Journal, v. 92, n. 368, dez, 1982, p. 886-902.

MORAES, M. A. F. D. O mercado de trabalho da agroindústria canavieira. Economia Aplicada, v. 11, n. 4, p. 605-619, out.-dez. 2007.

QUEIROZ, F. C. B. P. et al. Transformações no ensino superior brasileiro: análise das instituições privadas de ensino superior no compasso com as políticas de Estado. Ensaio: Avaliação e Políticas Públicas em Educação, Rio de Janeiro, v. 21, n. 79, p. 349-370, abr./jun. 2013.

RAMOS, L. Desigualdade de rendimentos do trabalho no período pós-real: o papel da escolaridade e do desemprego. Economia Aplicada, São Paulo, v. 11, n. 2, p. 281-301, jul. 2007.

SANTOS, A. L.; GIMENEZ, D. M. Inserção dos jovens no mercado de trabalho. Estudos Avançados, v. 29, n. 85, p. 154-168, 2015.

SCHULTZ, T. W. O capital humano: investimentos em educação e pesquisa. Rio de Janeiro: Zahar, 1973.

SILVA, C. M.; MENEZES FILHO, N.; KOMATSU, B. Uma abordagem sobre o setor de serviços na economia brasileira. São Paulo: INSPER - Centro de Políticas Públicas, ago. 2016. (Policy Paper, n. 19).

SMITH, A. A riqueza das nações: uma investigação sobre sua natureza e suas causas. 2. ed. São Paulo: Nova Cultural, 1995. v. 1.

SOARES, C.; OLIVEIRA, S. Gênero, estrutura ocupacional e diferenciais de rendimento. In: ENCONTRO NACIONAL DE ESTUDOS POPULACIONAIS, 14., 2004. Caxambu, MG. Anais... Caxambu, MG: ABEP, 2004.

VELOSO, F. A evolução recente e propostas para a melhoria da educação no Brasil. In: SCHWARTZMAN, S.; BACHA, E. L. Brasil: a nova agenda social. Rio de janeiro: LTC, 2011. p. 215-256.

Recebido em: 04/12/2014.

Aceito em: 22/06/2017. 